\title{
TATA LAKSANA BRAKHITERAPI CO-60 TEKNIK INTRAKAVITER LENGKAP PADA KASUS KANKER SERVIKS
}

\author{
Nugroho Yudho Susilo ${ }^{1)}$ Rini Indrati ${ }^{2)}$ Nanang Sulaksono ${ }^{3)}$ \\ ${ }^{1)}$ Rumah Sakit Adi Husada Cancer Center Surabaya \\ ${ }^{2,3)}$ Jurusan Teknik Radiodiagnostik dan Radioterapi Poltekkes Semarang
}

Mail :Yudho13579@gmail.com

\begin{abstract}
Background: Brachytherapy is a radiation treatment by bringing radiation sources closer to the primary tumor which aims to provide additional therapeutic doses (booster) after external radiation administration so that the optimal dose will be achieved. In general brachytherapy uses closed radioactive sources namely Radium, Cobalt-60, Cesium- 137, and Iridium-192.Intracaviter technique is a type of brachytherapy technique in which the radiation source is placed in a hilt and inserted into a body organ that contains a tumor. to obtain the optimal dose distribution.

Methods: The type of research used is qualitative research with a case study approach. The study was conducted by observation, documentation and interviews. The subjects of this study were one radiation oncology specialist, one medical physicist, one radiotherapy radiographer, and one radiotherapy nurse at the Radiotherapy Installation of Dr. Moewardi Hospital. Stages The data analysis in this study used the data analysis method which was done descriptively using interactive models.

Results: The results showed that the management of radiotherapy in cervical cancer patients at Radiotherapy Hospital Dr. The procedure consists of several procedures, namely the control of a specialist oncologist of radiation after external radiation, supporting examinations (check vital signs, laboratory, ECG, and chest X-ray), undergoing hospitalization a day before irradiation of brachytherapy, spinal anesthesia before applying the applicator, applying an applicator, simulating the position of the applicator with AP and Lateral x-ray projections, calculating the dose $(2 \times 850 \mathrm{cGy})$ and irradiation time in the TPS (Treatment Planning System) room based on the Manchester system dose distribution, and irradiation in the brachytherapy room.

Conclusion: Management of brachytherapy consists of several procedures, namely the control of radiation oncology specialists, supporting examinations, undergoing hospitalization the day before exposure, spinal anesthesia, applying applicators, simulating applicator positions, calculating doses and exposure time in the TPS (Treatment Planning System) ) based on the Manchester system dose distribution, and carried out irradiation in the brachytherapy room. The reason for using three Co-60 sources in one fraction of brachytherapy irradiation is because it can shorten the irradiation time and minimize the time error arising when the source moves. Evaluation of Co-60 brachytherapy patients in cervical cancer cases can be estimated in the form of tumor response, in patients experiencing total response and not experiencing side effects such as cystitis or progitis.
\end{abstract}

Keywords: Brachytherapy, Cobalt-60, Cervical Cancer

\section{Pendahuluan}

Kanker serviks merupakan tumor ganas yang menyerang squamosa intraepithelial serviks yang disebabkan oleh beberapa faktor. Menurut American Cancer Society (2014) faktor risiko yang dapat menyebabkan kanker serviks antara lain infeksi HPV (Human Papiloma Virus), merokok, penggunaan alat kontrasepsi, mengalami 3 atau lebih kehamilan, kehamilan pertama pada usia kurang dari 17 tahun, kemiskinan, immunosupresi, infeksi chlamydia, kurang konsumsi buah dan sayur, obesitas, penggunaan kontrasepsi oral dalam jangka waktu lama. Radioterapi memegang peranan penting dalam penanganan kanker serviks stadium awal, lokal lanjut, hingga paliatif, dan dapat diberikan sebagai terapi definitive atau sebagai terapi ajuvan setelah operasi (Wijokongko, 2016).

Penatalaksanaan kanker serviks dilakukan dengan pembedahan pada stadium 0 , I atau stadium IIA (FIGO), atau radiasi saja pada umumnya memberikan hasil pengobatan yang cukup baik. Radioterapi menjadi 
pengobatan terpilih pada kanker serviks uteristadium IIB-IVA karena efektif dan efisien dibandingkan dengan pembedahan ditambah kemoterapi. Radioterapi terdiri atas kombinasi radiasi eksterna dan brakhiterapi. Brakhiterapi merupakan komplemen metode teleterapi dengan cara memasang sumber radiasi ke dalam tumor. Disebut komplementari oleh karena brakhiterapi bertujuan untuk memberikan dosis terapi tambahan (booster) setelah pemberian radiasi eksterna sehingga akan tercapai dosis tumorisidal (Susworo, 2017).

Aplikasi tingkatan dosis pada brakhiterapi dikategorikan menjadi tiga sub kelompok, antara lain: tingkat dosis rendah low dose rate (LDR), 0,4-2 Gy/jam; tingkat dosis sedang medium dose rate (MDR), 2-12 Gy/jam; dosis tingkat tinggi high dose rate (HDR), >12 Gy/jam (Beyzadeoglu, 2010). Pada umumnya brakhiterapi menggunakan sumber radioaktif tertutup yaitu Radium, Cobalt-60, Cesium-137, dan Iridium192.Teknik intrakaviter merupakan salah teknik penempatan sumber brakhiterapi dimana sumber radiasi ditempatkan pada suatu gagang dan dimasukkan ke dalam organ tubuh yang mengandung tumor, seperti uterus atau vagina, maupun nasofaring.Jenis aplikator yang digunakan pada brakhiterapi yaitu silinder, ovoid, dan Rotterdam/fletcer.(Susworo, 2017).

Tatalaksana brakhiterapi diawali dengan pemeriksaan penunjang sebagai pendukung.Untuk memperoleh waktu rawatan yang pendek diperlukan sumber radioaktif yang mempunyai laju dosis tinggi.Dengan waktu rawatan yang pendek, pasien tidak memerlukan rawat inap, sehingga biaya bisa ditekan. Pada tindakan brakhiterapi perlu adanya simulator XRay C-Arm yang bertujuan untuk memverifikasi letak pemasangan aplikator sekaligus membantu dalam perhitungan dosis yang akan diterima baik dosis total atau batas dosis toleransi yang diterima organ sehat seperti kandung kemih serta rektum (Susworo, 2017).

Target volume radiasi sangat penting ditetapkan pada perencanaan radiasi (TPS), untuk menentukan penyebaran radiasi yang mencakup seluruh sasaran atau target radiasi (Rasjidi, 2011).Perhitungan yang memperlihatkan kemungkinan dosis lebih besar pada kandung kemih maupun rektum memerlukan tindakan koreksi, seperti metode pemberian radiasi maupun letak aplikator (Beyzadeoglu, 2010). Perhitungan dosis brakhiterapi pada intrakaviter dan intravaginal sampai saat ini masih mengacu pada titik A dan titik B sesuai metode Manchester (Komite Penanggulangan Kanker Nasional (KPKN) Serviks, 2017).

Pada Instalasi Radioterapi RSUD Dr. Moewardi dalam pelaksanaan brakhiterapi pada pasien kanker serviks stadium IIB menggunakan tiga sumber Co-60 dalam satu fraksi.Pasien dirawat inap selama satu hari sebelum dilakukan brakhiterapi untuk persiapan anestesi spinal.Pasien di simulasi menggunakan pesawat X-ray mobile dengan proyeksi orthogonal.Pemberian distribusi dosis brakhiterapi mengacu pada metode Manchester dengan teknik intrakaviter lengkap.Teknik intrakaviter lengkap yaitu dengan penggunaan 3 buah aplikator yang biasa disebut Fletcher atau Rotterdam (1 buah intrauterine dan 2 buah ovoid). Dosis radiasi yang diberikan 2 x 8,5 Gy per minggu sehingga target volume pada area tumor dapat terpapar radiasi maksimal dan memperhatikan paparan dosis toleransi pada organ at risk yaitu rektum dan vesika urinaria dari dosis total yang diberikan pada target tumor.

Berdasarkan uraian di atas penulis tertarik untuk membahas tatalaksana brakhiterapi pada kanker serviks dari segi penggunaan teknik intrakaviter lengkap, alasan penggunaan brakhiterapi tiga sumber Co-60 dalam satu kali tahap penyinaran, serta evaluasi pasien setelah selesai brakhiterapi, sehingga penulis tertarik untuk mengangkat kasus ini dalam tugas akhir dengan judul "Tatalaksana Brakhiterapi Co-60 Teknik Intrakaviter Lengkap Pada Kasus Kanker Serviks Di Instalasi Radioterapi RSUD Dr. Moewardi”.

\section{Metode}

Jenis penelitian pada penelitian ini ialah kualitatif dengan pendekatan studi kasus yang bertujuan untuk mengetahui tatalaksana brakhiterapi Co-60 teknik intrakaviter lengkap pada kasus kanker serviks di Instalasi Radioterapi RSUD Dr. Moewardi, alasan penggunaan tiga sumber dalam satu fraksi penyinaran, dan evaluasi pasien brakhiterapi Co-60 pada kasus kanker serviks.Pengambilan data penelitian dilakukan pada bulan Februari sampai dengan April 2019 dengan subjek yang berperan dalam penelitian ini adalah tenaga medis yang terkait yaitu dokter spesialis onkologi radiasi, fisikawan medis, radiografer radioterapi, dan perawat radioterapi di Instalasi Radioterapi RSUD Dr.Moewardi.TahapanAnalisis data dalam penelitian inimenggunakan metode analisis data yang dilakukan secara deskriptif menggunakan interaktif model.

\section{Hasil dan Pembahasan}

Brakhiterapi pada pasien kanker serviks menggunakan teknik intrakaviter lengkap di Instalasi Radioterapi RSUD Dr. Moewardi

a. Persiapan Sebelum (Pra) Brakhiterapi

1) Persiapan Pasien

Sebelum dilakukan tindakan brakhiterapi pasien dan keluarganya diberi penjelasan tentang jalannya pelaksanaan brakhiterapi serta dipersilahkan untuk menandatangani surat persetujuan dilakukan tindakan brakhiterapi. Pasien diprogram satu minggu atau tiga hari sebelum pelakasanaan brakhiterapi untuk cek laborat. Satu hari sebelum pelakasanaan brakhiterapi, pasien harus dirawat inap terlebih dahulu untuk melakukan beberapa persiapan seperti cukur rambut pubis (skeren) pada sore hari, minum obat pencahar sebagai pencahar agar colon dan rectum bersih dari feses, berpuasa selama 8 jam sebelum pelaksanaan brakhiterapi, dan diinfus sebelum beranjak ke Instalasi Radioterapi.

2) Persiapan Anestesi

a) Cek tanda-tanda vital

b) Pemeriksaan Laboratorium 
c) Pemeriksaan rekam jantung

d) Rontgen Thorax

b. Tatalaksana Brakhiterapi

1) Persiapan Pasien

Pasien dari bangsal sudah mengenakan baju operasi dan terpasang infus, dibawa ke ruang aplikasi di Instalasi Radioterapi untuk memulai tindakan pemasangan aplikator.Pasien diminta untuk duduk di meja khusus brakhiterapi.

2) Anestesi

Sebelum pemasangan aplikator brakhiterapi pasien terlebih dahulu dilakukan anestesi spinal oleh dokter spesialis anestesi supaya pasien tidak merasakan sakit. Anestesi dilakukan dengan cara menyuntikkan obat local (isobarik 12-15 mg / 2,5 cc) pada subaracnoid tulang belakang. Waktu onset pada pasien setelah penyuntikan 5 menit dipastikan dengan cara tes angkat kaki, tes cubit pinggang dan pundak. Waktu onset tersebut merupakan waktu yang terhitung saat obat diberikan hingga obat bereaksi. Obat anestesi ini akan bertahan selama 1,5 hingga 2 jam.

3) Pemasangan Aplikator

Setelah pasien teranestesi, pasien diposisikan litotomi, kaki pasien dibungkus menggunakan slup kaki, dan dilakukan pemasangan aplikator intrakaviter lengkap brakhiterapi untuk kanker serviks oleh dokter spesialis onkologi radiasi dibantu oleh perawat brakhiterapi. Tahap - tahap pemasangan aplikator brakhiterapi pada pasien adalah sebagai berikut :

a) Area vagina pasien desinfeksi menggunakan kassa dan betadine dengan cara memutar dari dalam keluar

b) Mengganti kassa untuk membersihkan intravagina

c) Memasang kateter uretra dengan menyuntikkan $3 \mathrm{cc} \mathrm{NaCl}$ sebagai kunci dan $50 \mathrm{cc} \mathrm{NaCl}$ media kontras Iopamiro untuk mengembungkan bulli

d) Menjepit kateter dengan klem untuk menjaga agar media kotras tidak mengalir ke luar melalui kateter

e) Membuka vagina menggunakan speculum $\operatorname{sim}$

f) Memasukkan sonde intrauteri ke kanalis serviks hingga menyentuh fundus uteri untuk mengukur kedalaman uterus lalu dicabut kembali

g) Memasukkan aplikator intrakaviter sesuai kedalaman sonde intrauteri

h) Memasukkan aplikator ovoid kanan dan kiri dimasukkan sampai menyentuh portio uteri

i) Merakit ketiga aplikator menjadi satu kesatuan

j) Memasang retraktor di bawah aplikator ovoid k) Memasukkan beberapa kassa sebagai fiksasi aplikator lalu diberi plester ke kulit panggul sebagai penahan kassa

1) Memasang kateter anus

m) Memasukkan rectal marker yang telah terbungkus kondom melalui anus

n) Menyuntikan larutan media kontras barium sebanyak $50 \mathrm{cc}$ kedalam anus melalui kateter

o) Mencabut kateter anus lalu diberi plester sebagai penahan rectal marker

p) Aplikator difiksasi dengan multi arm fixation supaya posisi tidak berubah saat simulasi dan terapi.

4) Simulasi

Setelah aplikator sudah terpasang pada pasien, selanjutnya dilakukan simulasi dengan tujuan untuk melihat letak aplikator dan untuk acuan dalam penghitungan dosis tumor serta organ kritis.Radiografer radioterapi menghidupkan alat brakhiterapi, X-ray mobile, dan CR. Tahap - tahap simulasi adalah sebagai berikut :

a) Pasien diminta tenang, tidak boleh bergerak selama simulasi berlangsung. Pertengahan sagital tubuh pasien tepat pada garis tengah meja supaya hasil simulasi benar-benar terukur

b) Digunakan posisi dari arah antero posterior dan Lateral untuk melihat aplikator berada tepat

c) Kemudian dibuat radiograf pelvis proyeksi Antero Posterior (AP) seperti pada gambar 4.3 dan Lateral seperti pada gambar 4.4 dengan arah sumbu sinar tegak lurus terhadap IP. Kedua radiograf dibuat magnifikasi yang sama yaitu jarak antara fokus ke film (FFD) $100 \mathrm{~cm}$.

d) Dalam pembuatan radiograf menggunakan IP ukuran 30x $40 \mathrm{~cm}$ sesuai ukuran scanner computer

e) Hasil radiograf seperti yang terlihat pada gambar 4.5 kemudian dikirim ke ruang Treatment Planning System (TPS) menggunakan flashdisk

5) Treatment Planning System (TPS)

Treatment Planning System (TPS) berfungsi untuk memodelkan aplikator dan jalannya sumber yang masuk ke aplikator, menghitung dan membuat distribusi dosis sesuai keputusan dokter, dan membuat optimasi dosis bila diperlukan.TPS memerlukan beberapa hal yaitu laju dosis sumber serta spesifikasinya, gambar radiograf posisi AP dan Lateral, dimensi dan kedalaman aplikator.Software yang digunakan yaitu GZP CO 60.Sistem perhitungan distribusi dosis menggunakan sistem Manchester.

6) Penyinaran Brakhiterapi

Pasien diantar masuk ke ruang penyinaran brakhiterapi, sebelumnya diberi penjelasan tentang jalannya penyinaran dan lamanya waktu 
penyinaran oleh Radiografer Radioterapi yang bertugas. Untuk pelaksanaan penyinaran dilakukan dengan langkah-langkah sebagai berikut :

a) Hasil perhitungan dosis dari komputer TPS dikirim ke dalam komputer kontrol pesawat brakhiterapi

b) Kemudian data dari TPS yang sudah tersimpan dalam dapat dilihat dalam monitor pesawat brakhiterapi pada aplikasi GZP3 Cobalt-60 Afterloading Therapy Unit, apabila data sudah benar sesuai dalam perencanaan pasien siap dilakukan penyinaran dengan data tersebut

c) Transfer tube dipasang pada aplikator sesuai dengan channel yang sudah ditentukan dan terkunci dengan indexer chanel. Kemudian pintu ruangan penyinaran ditutup dan dapat dilakukan penyinaran pada pasien

\section{c. Tindakan Setelah Brakhiterapi}

Penyinaran brakhiterapi dilakukan dua kali dengan interval enam hari atau satu minggu, tidak ada perawatan khusus selama tenggang brakhiterapi berikutnya hanya Infus tetap terpasang pada pasien selama tindakan hingga penyinaran brakhiterapi selesai.Setelah penyinaran brakhiterapi selesai, transfer tube dilepas dari aplikator.Pasien dibawa keruang khusus untuk melepas aplikator, marker, serta bahan-bahan yang digunakan sebagai fiksasi aplikator, dilakukan vulva hygiene, dan memasang pempers.Setelah selesai, pasien diperbolehkan makan dan minum.Pasien dapat dipersilakan kembali ke bangsal untuk pemulihan keadaan umum dari anastesi dengan infus masih terpasang pada pasien.Apabila pasien tidak mengalami perdarahan dan kondisi umum baik, pasien dapat dipersilakan pulang berdasarkan ijin dari dokter.

d. Penggunaan tiga sumber Co-60 dalam satu fraksi penyinaran brakhiterapi

Pesawat remote-afterloading brakhiterapi NPICEM di Instalasi Radioterapi RSUD Dr. Moewardi memiliki tiga buah sumber berupa Cobalt60. Dalam proses penyinaran, pesawat tersebut dapat diatur untuk mengeluarkan sumber satu per satu bahkan dua atau tiga sekaligus. Semua itu tergantung pada jumlah aplikator yang akan digunakan. Pada pasien brakhiterapi kanker serviks teknik intrakaviter lengkap menggunakan tiga aplikator, maka pesawat brakhiterapi diatur untuk mengeluarkan ketiga sumber tersebut secara bersamaan. Hal tersebut dapat mempercepat waktu penyinaran dan memperkecil time eror yang timbul saat sumber bergerak. Penggunaan sumber Cobalt-60 lebih efisien dalam ekonomi maupun penggunaan, karena Cobalt-60 memiliki waktu paruh yang cukup lama sehingga dalam pergantian sumber dan mengurus perijinan mendapat jeda waktu yang cukup lama pula. Namun terdapat kekurangan seperti total laju dosis yang lebih besar sehingga diperlukan dinding ruangan beserta kontener sumber yang lebih tebal.

e. Evaluasi pasien brakhiterapi Co-60 pada kasus kanker serviks

Di Instalasi Radioterapi RSUD Dr. Moewardi, pasien brakhiterapi pada kasus kanker serviks dilakukan evaluasi pertama oleh dokter spesialis onkologi radiasi pada saat fraksi brakhiterapi pertama. Evaluasi berupa pertimbangan antara hasil perhitungan dosis dan jumlah fraksi dari fisika medis dengan dosis yang diterima oleh tumor maupun organ at risk (OAR). Apabila dosis yang diterima oleh OAR melebihi batasan yang ditentukan, maka dokter akan memutuskan untuk menambah jumlah fraksi yang semula 2 x 850 cGy menjadi 3 x 700 cGy. Batas efisinsi waktu penyinaran antara fraksi pertama dengan fraksi selanjutnya berkisar dari 7 10 hari.

Pada saat penyinaran terakhir brakhiterapi, dokter sudah dapat memperkirakan tumor pada pasien mengalami parsial respon atau total respon. Pasien brakhiterapi juga dapat mengalami efek samping seperti kistitis maupun progtitis apabila hasil perhitungan dosis OAR yang kurang tepat. Hal tersebut dapat menjadi bahan pelaporan dokter spesialis onkologi radiasi kepada dokter pengirim. Setelah paket penyinaran brakhiterapi selesai, satu minggu atau satu bulan setelahnya pasien diminta datang kembali ke dokter spesialis onkologi radiasi untuk kontrol lalu dapat kembali ke dokter pengirim.

1. Tatalaksana brakhiterapi Co-60 teknik intrakaviter lengkap pada kasus kanker serviks di Instalasi Radioterapi RSUD Dr. Moewardi.

Instalasi Radioterapi RSUD Dr. Moewardi pada pasien kanker serviks sebelum penyinaran brakhiterapi, pasien beserta keluarganya diberi penjelasan tentang jalannya pelaksanaan brakhiterapi serta dipersilahkan untuk menandatangani surat persetujuan dilakukan tindakan brakhiterapi. Pasien akan diberikan jadwal penyinaran brakhiterapi. Satu hari sebelum pelakasanaan brakhiterapi, pasien harus dirawat inap terlebih dahulu untuk melakukan beberapa persiapan seperti cukur rambut pubis (skeren) pada sore hari, minum obat pencahar sebagai pencahar agar colon dan rectum bersih dari feses, berpuasa selama 8 jam sebelum pelaksanaan brakhiterapi, dan diinfus sebelum beranjak ke Instalasi Radioterapi. Pemeriksaan penunjang yang harus dilakukan pasien guna persyaratan anestesi yaitu cek tanda-tanda vital (suhu, tensi, nadi, dan respirasi), pemeriksaan laboratorium, pemeriksaan EKG (rekam jantung), dan rontgen thorax.

Menurut Susworo (2017), Pemeriksaan penunjang sebelum dilakukan treatment brakhiterapi : pertama, dilakukan pemeriksaan keadaan umum termasuk kelenjar getah bening terutama supraklavikula (kiri), palpasi hepar. Kedua, pemeriksaan klinis ginekologi antara lain inspeksi, 
palpasi bimanual pervagina dan per-rektal diikuti biopsy lesi tumor.Ketiga, pemeriksaan laboratorium yaitu hematologi rutin, kimia darah, fungsi hati, dan ginjal. Keempat, pemeriksaan radiologi foto thoraks, CT Scan, MRI, dan USG dilakukan pada pasien karsinoma serviks. Untuk memperoleh waktu rawatan yang pendek diperlukan sumber radioaktif yang mempunyai laju dosis tinggi.Dengan waktu rawatan yang pendek, pasien tidak memerlukan rawat inap, sehingga biaya bisa ditekan. Keadaan ini lebih menguntungkan bagi senter dengan jumlah pasien yang banyak.Kerana itu sejak beberapa dasawarsa lampau digunakan sumber Co-60 atau Ir192.

Sumber brakhiterapi yang digunakan yaitu Co60 yang mempunyai laju dosis tinggi dan menjadikan waktu rawatan pendek sehingga tidak memerlukan rawat inap.Akan tetapi pasien brakhiterapi Co-60 teknik intrakaviter lengkap pada kasus kanker serviks di Instalasi Radioterapi RSUD Dr. Moewardi harus menjalani rawat inap sehari sebelum penyinaran.Hal tersebut dilakuan untuk mendapatkan hasil yang maksimal dalam persiapan pasien.Persiapan tersebut bertujuan untuk membersihkan faeces yang berada di colon supaya tidak mengganggu gambaran pada radiograf, dan memberikan kenyamanan pasien.Persiapan pasien telah disesuaikan secara rinci dengan SOP (Standar Operasional Pelayanan).Pemeriksaan penunjang sebelum brakhiterapi pada pasien kanker serviks di Instalasi Radioterapi RSUD Dr. Moewardi sesuai dengan teori Susworo (2017).Beberapa pemeriksaan penunjang tersebut dilaksanakan untuk dijadikan bahan konsultasi tindakan anestesi.Apabila hasil pemeriksaan baik menurut dokter anestesi, maka penyinaran brakhiterapi dapat dilanjutkan.

Setelah pasien teranestesi, pasien diposisikan litotomi, kaki pasien dibungkus slup kaki, dan dilakukan pemasangan aplikator intrakaviter lengkap (Fletcher atau Rotterdam) dengan tahap - tahap sebagai berikut : area vagina dan intravagina pasien disinfeksi menggunakan kassa dan betadine, memasang kateter uretra dengan menyuntikkan $3 \mathrm{cc}$ $\mathrm{NaCl}$ sebagai kunci dan $50 \mathrm{cc} \mathrm{NaCl}$ media kontras kedalam bulli, menjepit kateter dengan klem, membuka vagina menggunakan speculum sim, memasukkan sonde intrauteri ke kanalis serviks lalu dicabut kembali, memasukkan aplikator intrakaviter sesuai kedalaman sonde intrauteri, memasukkan aplikator ovoid kanan dan kiri, merakit ketiga aplikator dalam satu kesatuan, memasang retraktor di bawah aplikator ovoid, memasukkan beberapa kassa sebagai fiksasi aplikator lalu diberi plester ke kulit panggul, memasang kateter anus, memasukkan rectal marker yang telah terbungkus kondom melalui anus, menyuntikan larutan media kontras barium sebanyak 50 cc kedalam anus melalui kateter, mencabut kateter anus lalu diberi plester sebagai penahan rectal marker, dan memfiksasi aplikator dengan multi arm fixation supaya posisi tidak berubah saat simulasi maupun terapi.

Penggunaan aplikator di Instalasi Radioterapi RSUD Dr. Moewardi yang sudah sesuai dengan teori Rasjidi (2011), bahwa pada pasien brakhiterapi kanker serviks teknik intrakaviter menggunakan aplikator Fletcher atau Rotterdam yang terdiri dari satu aplikator intrakaviter dan dua aplikator ovoid. Urutan pemasangan aplikator sudah sesuai dengan teori Susworo (2017) yaitu dengan memasang aplikator intrakaviter terlebih dahulu lalu memasang aplikator ovoid dan memfiksasi ketiga aplikator tersebut menjadi satu. Di Instalasi Radioterapi RSUD Dr. Moewardi menyuntikkan $50 \mathrm{cc} \mathrm{NaCl}$ media kontras kedalam bulli dan penyuntikan media kontras ke dalam rektum sebanyak $50 \mathrm{cc}$, sedangkan menurut teori Susworo (2017), bulli diisi kuranglebih $150 \mathrm{cc}$ air steril dan rektum di pasang marka logam (marker) tanpa penyuntikan media kontras ke dalam rektum. Kesenjangan tersebut tidak menjadi permasalahan yang serius selama tindakan tersebut masih dalam satu tujuan untuk mengetahui posisi organ at risk (OAR) brakhiterapi kanker serviks yaitu bulli dan rektum.

Di Instalasi Radioterapi RSUD Dr. Moewardi, simulasi setelah pemasangan aplikator dilakukan menggunakan pesawat X-Ray Mobile dan CR. Simulasi bertujuan untuk melihat letak aplikator dan untuk acuan dalam penghitungan dosis tumor serta organ kritis. Kemudian dibuat radiograf pelvis proyeksi Antero Posterior (AP) dan Lateral. Kedua radiograf dibuat magnifikasi yang sama yaitu jarak antara fokus ke film (FFD).

Menurut Susworo (2017), Pada tindakan brakhiterapi perlu adanya simulator X-Ray C-Arm yang bertujuan untuk memverifikasi letak pemasangan aplikator sekaligus membantu dalam perhitungan dosis yang akan diterima baik dosis total atau batas dosis toleransi yang diterima organ sehat. Pengambilan foto dibutuhkan pesawat X-Ray C-Arm serta ortogonal yang berfungsi untuk geometri menentukan posisi ideal agar presisi dalam penentuan hasil foto antero posterior (AP) dan Lateral dengan memperhatikan akurasi jarak, faktor pembesaran, dan mengetahui jarak aplikator ke kandung kemih serta rektum.

Simulasi di Instalasi Radioterapi RSUD Dr. Moewardi sesuai dengan teori Susworo (2017) yaitu dengan melakukan pemeriksaan radiografis orthogonal. Walaupun simulasi tidak menggunakan X-Ray C-Arm melainkan menggunakan X-Ray Mobile dengan $\mathrm{CR}$, akan tetapi pengambilan foto orthogonal tetap dapat dilaksanakan dengan baik dengan memperhatikan faktor-faktor yang ada agar dapat mengetahui jarak sebenarnya antara aplikator dengan OAR.

Proses TPS yang dilakukan di Instalasi Radioterapi RSUD Dr. Moewardi bertujuan untuk memodelkan aplikator dan jalannya sumber yang masuk ke aplikator, membuat optimasi dosis bila 
diperlukan dan memperhitungkan cakupan dosis paparan ke organ at risk (OAR) yaitu vesika urinaria dan rektum (70-80\%). Software yang digunakan pada TPS yaitu GZP CO 60. Sistem perhitungan distribusi dosis menggunakan sistem Manchester yang telah ditetapkan pada titik dose point atau reference point yaitu titik A kanan dan kiri.

Menurut Rasjidi (2011), Target volume radiasi sangat penting ditetapkan pada perencanaan radiasi (TPS), untuk menentukan penyebaran radiasi yang mencakup seluruh sasaran atau target radiasi. Komputer TPS secara otomatis akan menghitung dan menghasilkan gambaran distribusi dosis yang berguna untuk mengevaluasi besarnya dosis pada volume target atau OAR disekitarnya.Perhitungan yang memperlihatkan kemungkinan dosis lebih besar pada kandung kemih maupun rektum memerlukan tindakan koreksi, seperti metode pemberian radiasi maupun letak aplikator. Batas pemberian dosis toleransi pada organ sehat yaitu pada rektum $80 \%$, dan pada kandung kemih $85 \%$ dari perolehan dosis total yang diterima pada sel kanker (Beyzadeoglu, 2010).Berdasarkan Komite Penanggulangan Kanker Nasional (KPKN) Serviks (2017), Perhitungan dosis brakhiterapi pada intrakaviter dan intravaginal sampai saat ini masih mengacu pada titik A dan titik B sesuai metode Manchester.

Proses TPS di Instalasi Radioterapi RSUD Dr. Moewardi yang sudah sesuai dengan teori Rasjidi (2011), bahwa TPS bermanfaat untuk menghitung dosis, menentukan distribusi dosis dan memfokuskan dosis ke target dengan mempertimbangkan dosis pada OAR.Batasan dosis pada OAR masih dalam ambang batas sesuai dengan teori Beyzadeoglu (2010).Perhitungan dosis brakhiterapi intrakaviter lengkap sesuai dengan Komite Penanggulangan Kanker Nasional (KPKN) Serviks (2017) yaitu mengacu pada metode Manchester dengan titik dose point atau reference point.

Penyinaran brakhiterapi Co-60 pada pasien kanker serviks dengan teknik intrakaviter lengkap di Instalasi Radioterapi RSUD Dr. Moewardi diberikan sebanyak 2 kali (850 cGy per fraksi) dalam 2 minggu dengan dosis total 1700 cGy. Perubahan jumlah fraksi dapat terjadi apabila dosis yang diterima oleh OAR tidak sesuai dengan yang direncanakan.Hal ini sesuai dengan penyataan Rasjidi (2011), bahwa teknik pemberiannya adalah setelah radiasi eksterna (1-2 minggu setelah radiasi eksterna).Brakhiterapi diberikan dalam 2-3 fraksi dengan interval waktu 1 minggu diantara fraksi. Jeda satu minggu setelah radiasi eksterna diikuti dengan brakhiterapi sebanyak dua atau tiga kali dengan dosis masing-masing 8,5 Gy atau 7 Gy pada titik A (Susworo, 2017).

2. Penggunaan tiga sumber Co-60 dalam satu fraksi penyinaran brakhiterapi teknik intrakaviter lengkap pada kasus kanker serviks di Instalasi Radioterapi RSUD Dr. Moewardi.
Di Instalasi Radioterapi RSUD Dr. Moewardi menggunakan pesawat remote-afterloading brakhiterapi microselectron merk NPICEM yang memiliki 3 buah sumber berupa Cobalt-60. Dalam proses penyinaran, pesawat tersebut dapat diatur untuk mengeluarkan sumber satu per satu bahkan dua atau tiga sekaligus. Semua itu tergantung pada jumlah aplikator yang akan digunakan. Pada pasien brakhiterapi kanker serviks teknik intrakaviter lengkap menggunakan tiga aplikator, maka pesawat brakhiterapi diatur untuk mengeluarkan ketiga sumber Co-60 secara serempak.

Menurut Susworo (2017), Pada umumnya brakhiterapi menggunakan sumber radiasi tertutup. Brakhiterapi intrakaviter diberikan dengan HDR Iridium-192, Cobalt-60 atau MDR/LDR Caesium137.Pesawat yang digunakan adalah microselectron (mHDR), GammaMed, atau Selectron.Untuk memperoleh waktu rawatan yang pendek diperlukan sumber radioaktif yang mempunyai laju dosis tinggi. Co-60 mempunyai waktu paruh 5,26 tahun. Sumber harus terbungkus dengan pembungkus yang dapat bertahan pada suhu tinggi.Untuk mencegah bocor direkomendasikan menggunakan pembungkus ganda.Penggantian sumber harus dilakukan oleh personil yang cakap dan peralatan yang memadai didampingi PPR.

Sumber dan pesawat brakhiterapi di Instalasi Radioterapi RSUD Dr. Moewardi sudah sesuai dengan teori Susworo (2017). Dengan sumber Co-60 akan lebih efisien dalam ekonomi maupun pemanfaatan, karena sumber Co-60 memiliki waktu paruh yang cukup lama sehingga dalam pergantian sumber dan mengurus perijinan mendapat jeda waktu yang cukup lama pula. Akan tetapi, sumber Co-60 memiliki total laju dosis yang besar sehingga diperlukan dinding ruangan beserta kontener sumber yang lebih tebal.Pada brakhiterapi kanker serviks teknik intrakaviter lengkap menggunakan 3 aplikator, pesawat brakhiterapi diatur untuk mengeluarkan ketiga sumber tersebut secara serempak. Hal tersebut dapat mempersingkat waktu penyinaran dan memperkecil time eror yang timbul saat sumber bergerak dari kontener menuju aplikator maupun perpindahan antar step pada aplikator.

3. Evaluasi pasien brakhiterapi Co-60 pada kasus kanker serviks di Instalasi Radioterapi RSUD Dr. Moewardi.

Di Instalasi Radioterapi RSUD Dr. Moewardi, pasien brakhiterapi pada kasus kanker serviks dilakukan evaluasi pertama pada saat fraksi brakhiterapi pertama. Evaluasi berupa pertimbangan antara hasil perhitungan dosis dan jumlah fraksi dari fisika medis dengan dosis yang diterima oleh tumor maupun organ at risk (OAR). Apabila dosis yang diterima oleh OAR melebihi batasan yang ditentukan, maka dokter akan memutuskan untuk menambah jumlah fraksi yang semula 2 x 850 cGy menjadi 3 x 700 cGy. Pada saat penyinaran terakhir brakhiterapi, 
dokter sudah dapat memperkirakan tumor pada pasien mengalami parsial respon atau total respon.Pasien brakhiterapi juga dapat mengalami efek samping seperti sistitis maupun proktitis apabila hasil perhitungan dosis OAR yang kurang tepat.Akan tetapi sangat jarang ditemukan pasien pasca penyinaran brakhiterapi dengan keluhan efek samping tersebut.

Menurut Susworo (2017), Penilaian komplikasi radiasi pada organ sekitar dilakukan berdasarkan kriteria skoring menurut RTOG atau EORTC. Efek akut yang terjadi adalah sistitis akut yang ditandai dengan keluhan perasaan sering buang air kecil tetapi ternyata tidak ada yang keluar, dan progtitis berupa diare riangan.Keluhan ini pada umumnya dapat diatasi dengan pengobatan simptomatis.Sedangkan efek lanjut biasanya terjadi lewat 6 bulan setelah pengobatan berakhir. Efek lanjut yang berat terjadi akibat OAR menerima dosis berlebihan seperti terjadi penyusutan volume kandung kemih disertai perdarahan berulang akibat terjadinya teleangiektasi selaput lendir kandung kemih, dan pada rektum terjadi berupa fibrotik dinding anterior rektum yang seringkali mengekibarkan perdarahan saat buang air besar.

Apabila dosis yang diterima oleh OAR melebihi batasan yang ditentukan, maka akan memutuskan untuk menambah jumlah fraksi yang semula 2 x 850 cGy menjadi 3 x 700 cGy, penambahan jumlah fraksi tersebut akan menurunkan dosis penyinaran tiap fraksinya akan tetapi tumor tetapi mendapatkan dosis yang optimal. Hal tersebut berpengaruh pada OAR yang mendapat dosis perfraksi yang lebih ringan sehingga pemulihan sel rusak tidak memakan waktu lama.Efek samping brakhiterapi kanker serviks teknik intrakaviter lengkap yang dapat terjadi pada OAR sesuai dengan teori Susworo (2017) yaitu sistitis dan proktitis. Perhitungan dosis dan simulasi yang dilakukan di Instalasi Radioterapi RSUD Dr. Moewardi sudah tepat, sehingga pasien mengalami total respon dan tidak mengalami efek samping berupa sistitis dan proktitis.

\section{Simpulan}

Berdasarkanpembahasan tatalaksana brakhiterapi teknik intrakaviter lengkap pada kasus kanker serviks di Instalasi Radioterapi RSUD Dr. Moewardi, dapat ditarik kesimpulan bahwa tatalaksana brakhiterapi terdiri dari beberapa prosedur yaitu kontrol dokter spesialis onkologi radiasi, dilakukan pemeriksaan penunjang, menjalani rawat inap sehari sebelum penyinaran, dilakukan anestesi spinal, dilakukan pemasangan aplikator, simulasi posisi aplikator, melakukan perhitungan dosisdan waktu penyinaran di ruang TPS (Treatment Planning System) berdasarkan distribusi dosis sistem Manchester, dan dilaksanakan penyinaran di ruang brakhiterapi.Alasan penggunaan tiga sumber Co-60 dalam satu fraksi penyinaran brakhiterapi dikarenakan dapat mempersingkat waktu penyinaran dan memperkecil time eror yang timbul saat sumber bergerak. Evaluasi pasien brakhiterapi Co-60 pada kasus kanker serviks sudah dapat diperkirakan berupa respon tumor, pada pasien mengalami total respon dan tidak mengalami efek samping seperti kistitis maupun progtitis.

\section{Daftar Pustaka}

American Cancer Society. (2014). Cervical Cancer Prevention and EarlyDetection.

Beyzadeoglu M, Ebruli C, Ozyigit G. (2010). Basic Radiation Oncology. Springer. New York.

Komite Penanggulangan Kanker Nasional (KPKN) Serviks. (2017). Panduan Penatalaksanaan Kanker Serviks, Kementrian Kesehatan RI.

Rasjidi, Imam. Supriana, Nana dan Cahyono, Kristianus. (2011). Radioterapi Pada Keganasan Ginekologi. Cetakan 1. Jakarta.

Susworo, R. (2017). Dasar-dasar Radioterapi Tata Laksana Radioterapi Penyakit Kanker. Universitas Indonesia. Jakarta.

Wijokongko, Sigit. Ardiyanto, Jefri. Fatimah, dkk (2016). Protokol Radiologi, Magelang 